\title{
НЕКОТОРЫЕ ВОПРОСЫ РЕФОРМИРОВАНИЯ ИНСТИТУТА ПРЕКРАЩЕНИЯ ОБЯЗАТЕЛЬСТВ
}

В настоящее время в России ведется активная работа по реформированию гражданского законодательства. Подготовленный Проект изменений в ГК РФ ${ }^{1}$ затрагивает практически все институты гражданского законодательства, в том числе и институт прекращения обязательств. Отдельным «новеллам», предлагаемым Проектом, и посвящена настоящая статья.

\section{І. Зачет}

А. Предпосылки зачета. Зачет (компенсаиия) представляет собой способ прекращения взаимных требований двух лиц, каждое из которых является одновременно и должником, и кредитором.

Для того, чтобы наступила возможность зачета, должны быть выполнены определенные позитивные и негативные предпосылки.

Позитивные предпосылки зачета (встречность требований, однородность требований, осуществимость активного требования, исполнимость пассивного требования) отражены в предписаниях ст. 410 ГК РФ. Несмотря на то, что концепция совершенствования общих положений обязательственного права ${ }^{2}$ предполагала решение ряда вопросов, связанных с регулированием позитивных предпосылок зачета, ${ }^{3}$ последние так и не стали объектом внимания со стороны разработчиков Проекта изменений в ГК РФ.

1 Проект Федерального закона РФ «О внесении изменений в части первую, вторую, третью и четвертую Гражданского кодекса Российской Федерации, а также в отдельные законодательные акты Российской Федерации» (Проект № 47538-6, в ред. принятой ГД РФ в первом чтении 27 апреля 2012 г.)// http://base. consultant.ru/cons/cgi/online.cgi?req=doc;base=LAW; $n=128204$

2 Концепция совершенствования общих положений обязательственного права России// http://www.privlaw. ru/index.php?section_id=24

3 Так, п. 2.3.2 концепции ОПОП выдвигал проблему т.н. «юридической» однородности зачитываемых требований. 
Напротив, регулирование негативных предпосылок (случаев недопустимости) зачета, закрепленных в ст. 411 ГК РФ, подверглось в Проекте определенному реформированию.

Прежде всего, перечень случаев недопустимости зачета предлагается дополнить указанием на требования, вытекающие из натуральных обязательств.

Оценивая данное предложение, следует иметь в виду, что наступление срока является лишь одним из показателей осуществимости активного требования как позитивной предпосылки зачета. В этой связи в литературе указывалось: «при толковании действующего текста ст. 410 ГК РФ необходимо учитывать, что зачет представляет собой «суррогат» исполнения, и при этом, поскольку осуществляется посредством одностороннего преобразовательного акта компенсанта (заявителя), несет в своем механизме некий элемент принудительности в отношении компенсата (адресата заявления). Соответственно необходимо обеспечить, чтобы положение последнего в результате зачета не ухудшилось, по сравнению с тем, каковым бы оно было при предъявлении к компенсату требования об исполнении». ${ }^{4}$ На это обстоятельство обращали внимание и составители международных унификаций. Так, ст. 8.1 (1b) Принципов международных коммерческих договоров УНИДРУА текстуально воплощает предпосылку осуществимости активного требования фразой «срок исполнения обязательства другой стороны наступил». Однако раскрывая содержание этой предпосылки, официальный комментарий указывает: «Поскольку натуральное или моральное обязательство не подлежат принудительному исполнению, первая сторона не может осуществить зачет против такого обязательства, имеющегося у другой стороны». ${ }^{5}$ Аналогичным образом официальный комментарий к ст. 13:101 Принципов Европейского договорного права раскрывает соответствующую предпосылку («cross-claim due») посредством указания на осуществимость («enforceable») такого требования. ${ }^{6}$

В этой связи предложение Проекта выглядит определенным дублированием существующего регулирования и, по сути, не вносит в него изменений. Вместе с тем нормативная техника решения соответствующего вопроса вызывает большие опасения. Включение натуральных требований в перечень ст. 411 ГК РФ («случаи недопустимости зачета») может создать у участников оборота ложное представление о невозможности их использования для зачета ни в качестве активных, ни в качестве пассивных. Однако подобный запрет не

4 Комментарий к Гражданскому кодексу Российской Федерации. Часть первая/ Под ред. А.П. Сергеева. М., 2010. С. 837 (автор комментария - А.А. Павлов).

5 Принципы международных коммерческих договоров УНИДРУА 2004. М., 2006. С. 288

6 При этом специально подчеркивается, что обязательство, в содержание которого входит активное требование, не должно относиться к натуральным («the cross-claim must not relate to a naturalis obligatio» (Principles of European Contract Law: Parts III / Ed. by O.Lando, E.Clive, A. Prüm and R. Zimmermann / Ed. by O. Lando, E. Clive, A. Prüm and R. Zimmermann. The Hague, London, New York, 2003. P. 140). 
соответствует идеям свободы и автономии субъектов гражданского оборота и явился бы неоправданным вмешательством в частные дела. как указывалось выше, задача законодателя состоит в защите интересов компенсата, как лица, не принимающего участия в зачете, а отнюдь не в ограничении динамики натуральных требований. В этой связи более удачным выглядело бы нормативное решение, наглядно демонстрирующее невозможность одностороннего зачета с требованием из игры или пари или иным натуральным требованием, но указывающее на допустимость зачета против подобных требований.

Еще одним предложением по реформированию предписаний, посвященных негативным предпосылкам зачета, является корректировка правил о зачете задавненных требований.

В действующей редакции абз. 2 ст. 411 ГК РФ к числу «случаев недопустимости зачета» отнесена ситуация, «если по заявлению другой стороны к требованию подлежит применению срок исковой давности и этот срок истек».

При всей очевидности идеи законодателя (состоящей опять же в защите интересов компенсата, как должника по задавненному требованию), с позиций нормативной техники указанные положения абз. 2 ст. 411 ГК РФ двусмысленны и некорректны. Они не учитывают изменившейся концепции применения института исковой давности («судом по заявлению стороны в споре»), а потому их практическое использование наталкивается на ряд серьезных проблем. Ведь если заявление о зачете осуществляется вне рамок судебного разбирательства, применение исковой давности к такому требованию с позиций действующего российского законодательства оказывается невозможным. В этой связи судебно-арбитражная практика признала, что сторона, получившая заявление о зачете задавненного требования, не обязана заявлять о пропуске исковой давности. Она может принудительно реализовать свое требование, объявив произведенный зачет ничтожным со ссылкой на истечение срока исковой давности в отношении встречного требования. ${ }^{7}$ Подобный подход только формально соответствует закону, и вносит неопределенность в положение лица, заявившего о зачете, а также создает возможность для злоупотреблений со стороны должника по задавненному требованию (компенсата). Ведь не заявляя о намерении использовать для своей защиты исковую давность, он недобросовестно создает у другой стороны уверенность в результативности произведенного зачета.

К сожалению, предложения Проекта изменений в ГК РФ не решают ни одну из обозначенных проблем. к числу случаев недопустимости зачета Проект

7 См. п. 10 Информационного письма Президиума ВАС РФ от 29 декабря 2001 г. № 65 «Обзор практики разрешения споров, связанных с прекращением обязательств зачетом встречных однородных требований»// Вестник ВАС РФ. 2002. № 3. 
относит «требования, по которым истек срок исковой давности». Тем самым на законодательном уровне предпринята попытка «реставрации» предписаний п/п. 1 ст. 230 ГК РСФСР 1964 г. а вместе с ней и абсолютный запрет на зачет задавненных требований. Подобное решение крайне неудачно. Исключение задавненных требований из числа зачетоспособных не может быть оправдано публичными интересами. Задача законодателя состояла лишь в защите частных интересов компенсата (должника по задавненному требованию). Последнее не может быть принудительно реализовано (абз. 2 п. 2 ст. 199 ГК РФ). А поскольку зачет является «суррогатом» исполнения и обладает свойством принудительности, правила о зачете не должны создавать возможность обхода соответствующих установлений.

Таким образом, законодатель должен был обеспечить компенсату возможность использовать ссылку на истечение давностного срока в качестве механизма защиты, но не может и не должен навязывать ему такую защиту. Для этого следовало бы использовать положительный опыт международных унификаций, рассматривающих задавненное требование способным к зачету в качестве активного, если должник не заявит об истечении исковой давности ранее или не об этом в течение двух месяцев после заявления о зачете. ${ }^{8}$

Хотя концепция совершенствования общих положений обязательственного права провозгласила ориентир на международные принципы договорного права, указанные правила, к сожалению, остались без должного внимания разработчиков Проекта изменений в ГК РФ.

Б. Момент действия зачета. Одним из наиболее важных вопросов института зачета является определение момента прекращения зачитываемых требований.

В современном российском законодательстве этот вопрос не решен. В судебно-арбиражной практике выдвинут подход, согласно которого если встречные требования являются однородными, срок их исполнения наступил и одна из сторон сделала заявление о зачете, то обязательства считаются прекращенными в момент наступления срока исполнения того обязательства, срок исполнения которого наступил позднее, и независимо от того, когда было сделано или получено заявление о зачете. ${ }^{9}$ Таким образом, Президиум ВАС РФ при-

8 Подобные правила закреплены в ст. 10.10. Принципов международных коммерческих договоров УниДРУА, ст. 14:503 Принципов Европейского договорного права, ст. III. - 7:503 DCFR.

9 См. п. 3 Информационного письма Президиума ВАС РФ от 29 декабря 2001 г. № 65 «Обзор практики разрешения споров, связанных с прекращением обязательств зачетом встречных однородных требований»// Вестник ВАС РФ. 2002. № 3. 
шел к выводу, что заявление о зачете обладает обратной силой (ретроактивным эффектом). ${ }^{10}$

Данный подход получил неоднозначную оценку в отечественной цивилистической доктрине. Отдельные исследователи, считая явление обратной силы неотъемлемой характеристикой зачета, всецело поддержали предложенную ВАС РФ концепцию. ${ }^{11}$ Другие, напротив, указывали, что современное законодательство оснований для подобного вывода не дает. ${ }^{12} 13$

Следует отметить, что проблема определения момента действия зачета характерна не только для российского законодательства. Отдельные правовые системы (например, скандинавских стран, Египта ${ }^{14}$ ) не признают феномена обратной силы, полагая действие зачета с момента заявления. Напротив, во многих национальных правопорядках, например, в Германии (§ 389 BGB), Швейцарии (abs. 2 art. 124 OR), Греции (art. 441 Astikos Kodikas), Португалии (art. 854 CC), Словении (§ 312 (2) LOA) и ряде других ${ }^{15}$ предусмотрены правила, устанавливающие ретроактивное действие заявления о зачете.

Вместе с тем, в современной зарубежной доктрине придание заявлению о зачете обратной силы подвергается критике. ${ }^{16}$ Действительно, ссылки сторонников ретроактивного эффекта зачета в обоснование этой концепции

10 Стоит, однако, обратить внимание на непоследовательность высшей судебной инстанции в отстаивании данного подхода. В том же Информационном письме № 65 Президиум ВАС РФ как минимум дважды (п.п. 10 и 14) делает выводы, вступающие в определенное противоречие с концепцией ретроактивности зачета.

11 См., напр.: Сарбаш С.В. Прекращение обязательств зачетом в арбитражной практике// Хозяйство и право. 2001. № 10. С. 87; крашенинников Е.А. О моменте действия одностороннего зачета// Очерки по торговому праву. Ярославль, 2011. Вып. 18. С. 5-7; Бевзенко Р.С., Фахретдинов Т.Р. Зачет в гражданском праве: Опыт исследования теоретической конструкции и обобщения судебной практики. М., 2006. С. 115-117.

12 См., напр.: Васильев Г.С. Вопросы применения зачета взаимных требований// Труды по гражданскому праву: к 75-летию Ю.к. Толстого. М., 2003. С. 216; Павлов А.А. Момент прекращения обязательств зачетом (к вопросу о феномене «обратной силы»)// Арбитражные споры. 2006. № 4. С. 111-118.

13 Дискуссия о моменте прекращения зачитываемых обязательств не является новой для отечественной доктрины. В дореволюционной литературе К. Анненков высказывался за зачет с момента заявления (Анненков К. Система русского гражданского права. Т. 3. Права обязательственные. СПб., 1901. С. 459460), Н.Г. Вавин - с момента наступления обстоятельств, дающих право на зачет (Вавин Н.Г. Зачет обязательств. Изд-е 2-е. М., 1914. С. 30-32). Сторонниками признания обратной силы зачета в советское время выступали М.М. Агарков (Гражданское право/ под ред. М.М. Агаркова и Д.М. Генкина. М., 1944. Т. 1. С. 389), И.Б. Новицкий (Новицкий И.Б. Обязательственное право. Общие положения: комментарий к ст. 106-129. М., 1925. С. 83) и Л.А. Лунц (Новицкий И.Б., Лунц Л.А. Общее учение об обязательстве. М., 1950. С. 403).

14 Подробнее см.: Principles of European Contract Law: Parts III / Ed. by O. Lando, E. Clive, A. Prüm and R. Zimmermann. P. 153; Principles, Definitions and Model Rules of European Private Law. Draft Common Frame of Reference (DCFR). 6 Volumes/ Ed. by C. von Bar and E. Clive. Oxford, 2010. P.1132-1133; Working Group for the preparation of Principles of International Commercial Contracts: Summary records of the meeting held in Rome from 3 to 7 June 2002 (Prepared by the Secretariat of UNIDROIT). Rome, September 2002 (UNIDROIT 2002. Study L - Misc. 24, paras. 333-334).

15 Подробнее см.: Principles of European Contract Law: Parts III / Ed. by O. Lando, E. Clive, A. Prüm and R. Zimmermann. P. 153; Principles, Definitions and Model Rules of European Private Law. Draft Common Frame of Reference (DCFR). 6 Volumes/ Ed. by C. von Bar and E. Clive. P.1132-1133.

16 См.: Zimmermann R. Comparative foundations of a European law of set-off and prescription. Cambridge Univ. Press, 2002. P. 39-40; Principles of European Contract Law: Parts III.P. 153. 
на «потребности жизни», «подразумеваемые интересы сторон», идеи добросовестности и справедливости ${ }^{17}$, выглядят достаточно спекулятивно.

Свой интерес стороны наглядно демонстрируют своим поведением. И если они не делают заявления о зачете, следовательно, они не желают прекращения соответствующих требований. Утверждать обратное, значит, противоречить действительности. Если же «лицо не подозревает о возможности прекратить обязательства зачетом, то оно и не может надеяться на предоставление ему какой-либо защиты. Выгоды, возникающие для этого лица при режиме ретроактивного действия, окажутся для него неожиданной удачей». ${ }^{18}$

Попытка представить отказ от ретроактивности при зачете требований, выраженных в различных валютах, как потакание «спекулированию» и недобросовестной наживе на изменении курсов валют, также лишена основания. Подобная ситуация вполне прогнозируема и в рамках противоположного подхода. По признанию видного немецкого компаративиста P. Schlechtriem'a, феномен ретроактивности также покровительствует такому «спекулированию». Основываясь на выгодности для себя того или иного курса, должник может выбирать, каким образом ему погашать обязательство - исполнением (платежом) или зачетом. ${ }^{19}$

Доводы практического характера, на которые ссылаются в обоснование ретроактивности зачета отдельные исследователи, также мало убедительны. Так, трудности в точном установлении даты прекращения зачитываемых требований при перспективном действии зачета ${ }^{20}$ сильно преувеличены. Случаи, когда они действительно способны возникнуть, единичны. Сами же эти трудности вполне преодолимы и вряд ли так велики, чтобы ради них «принести в жертву теоретическую чистоту» концепции «перспективного» действия зачета, как того требуют сторонники противоположного подхода.

К тому же, идея ретроактивности зачета таит в себе куда большие практические затруднения, поскольку «делает во всяком случае необходимой ревизию правоотношений сторон, сложившихся к моменту, когда одной из сторон сделано заявление о зачете встречного однородного требования». ${ }^{21}$

17 Обзор соответствующей аргументации см.: Zimmermann R. Op. sit. P. 39.

18 Zimmermann R. Op. sit. P. 39-40.

19 См.: Working Group for the preparation of Principles of International Commercial Contracts: Summary records of the meeting held in Rome from 3 to 7 June 2002 (Prepared by the Secretariat of UNIDROIT). Rome, September 2002 (UNIDROIT 2002. Study L - Misc. 24, paras. 330).

20 См.: Working Group for the preparation of Principles of International Commercial Contracts: Set-Off (Position paper prepared by Professor C. Jauffret-Spinosi). Rome, January 2000 (UNIDROIT 2000. Study L - Doc. 62-bis).

21 Витрянский В.В. Вопросы реформирования общих законоположений об обязательствах// Развитие основных идей Гражданского кодекса России в современном законодательстве и судебной практике. М., 2011. C. 228. 
С позиций ретроактивного действия зачета остается открытым целый ряд проблем. В частности, не ясно как быть с уже уплаченными процентами ${ }^{22}$, взысканными за период просрочки штрафными санкциями (тем более что процессуальные механизмы их возврата могут быть уже исчерпаны). Перечень этих проблем можно продолжать достаточно долго. ${ }^{23}$ Отсутствие же в национальном законодательстве их адекватных и действенных решений таит в себе значительную угрозу для стабильности оборота, а иногда даже открывает возможность для злоупотреблений.

В целом, несмотря на достаточно широкое отражение феномена обратной силы зачета в национальных законодательствах, аргументы, приводимые в его обоснование далеко не бесспорны, зачастую базируются лишь на традиционности подхода. как метко отметил R. Zimmermann: «Многое из сказанного защитниками ретроактивности зачета внушено необоснованной верой в то, что эта идея внутренне связана с «сущностью» зачета. Исторически, мы вероятно имеем дело с необдуманным перенесением предложений системы ius commune». ${ }^{24}$

В этой связи показательно, что современные международные унификации предусматривают исключительно перспективный эффект действия одностороннего зачета - с момента заявления. Подобные правила закреплены в ст. 8.5 (3) Принципов международных коммерческих договоров УНИДРУА, ст. 8/5 Проекта OHADA, ст. 13:106 Принципов Европейского договорного права и ст. III. - 6:107 DCFR. Распространение действия зачета только на будущее время представляется разработчикам указанных унификаций более естественным правилом, и приводит, по их мнению, к наиболее адекватному результату. ${ }^{25}$

Данный опыт международных принципов договорного права был воспринят при совершенствовании российского законодательства. Так, Проект изменений в ГК РФ предлагает дополнение ст. 410 ГК РФ положением о том, «обязательство считается прекращенным с момента получения заявления стороны о зачете встречного однородного требования другой стороной». С принятием данных изменений вопрос о моменте действия зачета наконец-то будет решен на законодательном уровне, а отечественный правопорядок получит регули-

22 Не случайно, отдельные правопорядки, предусматривая ретроактивный эффект заявления о зачете, делают специальную оговорку для уже уплаченных процентов. Так, § 197(2) эстонского LOA устанавливает, что если проценты уже были уплачен по одному или по обоим требованиям, зачетом не может быть охвачен период сверх последнего периода, за который уплачены проценты.

23 Подробнее см.: Павлов А.А. Момент прекращения обязательств зачетом (к вопросу о феномене «обратной силы»). С. 116-117.

24 Zimmermann R. Op. sit. P. 40.

25 См.: Принципы международных коммерческих договоров УнИДРУА 2004. М., 2006. С. 294-295; Principles of European Contract Law: Parts III / Ed. by O. Lando, E. Clive, A. Prüm and R. Zimmermann. P. 151-152, 153-154; Principles, Definitions and Model Rules of European Private Law. Draft Common Frame of Reference (DCFR). 6 Volumes. P. 1131-1132, 1133-1134 
рование, соответствующее новейшим общеевропейским и общемировым тенденциям, ратующим за исключительно «будущий» эффект заявления о зачете.

\section{II. Отступное}

А. «Правопрекращающий» эффект отступного. Действующее российское законодательство, посвященное отступному (datio in solutum), достаточно лаконично. Предписания ст. 409 ГК РФ дают основание утверждать, что механизм отступного включает в себя: (1) соглашение сторон об отступном и (2) фактическую передачу отступного взамен исполнения. При этом обязательство прекращается только в момент фактического предоставления отступного.

При этом данные законоположения не позволяют дать однозначного ответа на вопрос о правовой природе отступного и его «прекращающем» эффекте. Вопрос, который является объектом жарких дискуссий в современной российской доктрине. В судебно-арбитражной практике последних лет возобладало мнение, согласно которого соглашение об отступном является консенсуальной обязательственной сделкой. Совершение соглашения об отступном приводит к появлению правовых последствий, но не прекращает обязательство. Во временном промежутке между моментом заключения соглашения об отступном и предоставлением отступного, правовую связь должника и кредитора следует охарактеризовать как факультативное обязательство. Соответственно, должник обладает возможностью замены первоначального варианта исполнения предоставлением отступного, а кредитор имеет право требования лишь в отношении первоначального предмета исполнения. ${ }^{26}$

Подобный подход имеет очевидные достоинства. Во-первых, он соответствует нормативным указаниям ст. 409 ГК РФ. Факультативный предмет («суррогат») не выступает предметом обязательства, не является задолженным, а предоставляется именно «взамен» исполнения. ${ }^{27}$ Во-вторых, его применение позволяет четко отграничить отступное от новации, при которой само соглашение сторон влечет прекращение первоначального обязательства. ${ }^{28}$

26 См. п. 1 Информационного письма Президиума ВАС РФ от 21 декабря 2005 г. № 102 «Обзор практики применения арбитражными судами статьи 409 ГК РФ»// Вестник ВАС РФ. 2006. № 4.

Догматическое обоснование подобного подхода см.: Рохлин А. Юридические особенности отношений из отступного// Хозяйство и право. 2002. № 7. С. 56; Аминов Е.Р. Новация в российском гражданском праве: Дисс. канд. юрид. наук. Екатеринбург, 2011. С. 114-117.

27 Это не игнорируется авторами, настаивающими, что во временном промежутке между моментом заключения соглашения об отступном и предоставлением отступного, правовую связь должника и кредитора следует охарактеризовать как альтернативное обязательство. Соответственно, у должника первоначально имеется право выбора одного из предметов исполнения, а после осуществления им этого права - обязанность предоставить предмет отступного (см.: каган Е. Соглашение о новации или соглашение об отступном // ЭЖ-Юрист. 1999. № 19. С. 3).

28 Эта грань становится неочевидной при принятии концепции соглашения об отступном, порождающего альтернативное обязательство, а также в случае признания допустимым в зависимости от усмотрения 
Однако указанный подход характеризуется и рядом недостатков. Прежде всего, он лишает институт факультативных обязательств самостоятельного значения, допуская полное отождествление datio in solutum с осуществлением facultas alternativa должника. кроме того, при таком подходе «по сути игнорируются права и законные интересы кредитора, которому предлагается еще раз положиться на должника, однажды уже допустившего нарушение первоначального обязательства». ${ }^{29}$

Указанные недостатки послужили основанием для поиска иных вариантов объяснения правовой природы и правопрекращающего эффекта отступного. Разработчиками концепции совершенствования общих положений обязательственного права были предложены два рабочих варианта. «Во-первых, можно рассматривать в качестве отступного принятие кредитором иного исполнения взамен надлежащего, осуществляемое им с выдачей должнику расписки или иного документа, подтверждающего получение исполнения. Во-вторых, допустим подход, в соответствии с которым необходимо заключение соглашения сторон об отступном, порождающего право кредитора требовать на свой выбор при непредставлении ему отступного передачи ему либо предмета первоначального обязательства, либо непосредственно отступного. Таким образом, соглашение об отступном повлечет возникновение альтернативного обязательства». В Проекте изменений в ГК РФ воплощен первый из них - соглашению об отступном придан характер реальной сделки.

Подобный подход не является новым ни для отечественной, ${ }^{30}$ ни для зарубежной ${ }^{31}$ цивилистической доктрины. Он лишен обозначенных выше недостатков и в явно выгодную сторону отличается от предлагавшегося варианта «альтернативности». Вместе с тем, сам по себе этот подход не идеален. В литературе уже обращалось внимание, что понятие реального договора «входит в категориальный аппарат учения обосновании обязательства, в то время как datio in solutum служит основанием прекращения обязательства. кроме того, в самом понятии реального договора заложено, что он связан с вещами, которые передаются в собственность или во владение, тогда как предметом предоставления вместо исполнения могут быть не только вещи, но и требования». ${ }^{32}$ В этой связи более удачным был бы подход, согласно которому соглашение

сторон определить правовую связь должника и кредитора во временном промежутке между моментом заключения соглашения об отступном и предоставлением отступного как альтернативное или как факультативное обязательство (См.: Бациев В.В. Обязательство, осложненное условием об отступном (замене исполнения). М., 2003. С. 102-103).

29 Витрянский В.В. Вопросы реформирования общих законоположений об обязательствах. С. 227.

30 См., напр.: Бабаев А.Б. Соглашение о новации, предоставлении отступного и прощение долга// Законодательство. 2001. № 9. С. 17.

31 Подробнее см.: Крашенинников Е.А. К проблематике предоставления вместо исполнения// Очерки по торговому праву. Ярославль, 2002. Вып. 9. С. 36. 
об отступном, представляя собой лишь элемент фактического состава, не рассматривалось бы в качестве обязательственной сделкой.33 Однако, видимо, скудность гражданско-правового инструментария, имеющегося в распоряжении отечественного законодателя, не позволила воплотить данный подход.

Вызывает определенные возражения и нормативная техника, воплощающая указанное предложение. По смыслу п. 2 ст. 433 ГК РФ, реальный характер гражданско-правовой сделки должен быть предусмотрен законом. Однако в качестве реальной сделки отступное определяется лишь в Пояснительной записке к Проекту изменений в ГК РФ ${ }^{34}$, которая сама по себе регулятором гражданских правоотношений не является и возможность использования которой для толкования предписаний ГК РФ вызывает определенные сомнения. В то же время текст измененной ст. 409 ГК РФ исчерпывается следующим: «По соглашению сторон обязательство может быть прекращено предоставлением отступного: уплатой денежных средств или передачей иного имущества». Буквальное прочтение данных предписаний не способно очевидно обосновать реальный характер соглашения об отступном, а следовательно породит для участников оборота трудности понимания законодательной конструкции.

Б. Предмет отступного. В качестве возможных предметов отступного действующая редакция ст. 409 ГК РФ называет уплату денег и передачу имущества. При этом открытый характер перечня возможных предметов отступного, дает основание признать возможным предоставление в качестве отступного требований, в том числе воплощенных в ценных бумагах ${ }^{35}$, иных имущественных прав (например, исключительных). Догматически обосновывается допустимость предоставления отступного в виде результата работ или оказания услуг. ${ }^{36}$

К сожалению, предлагаемая Проектом изменений в ГК РФ редакция ст. 409 ГК РФ лишает соответствующий перечень открытого характера. С учетом того, что соответствующее предложение об ограничении предметов отступного не выдвигалось ни в концепции совершенствования общих положений обязательственного права, ни в концепции развития гражданского законода-

33 См.: Бабаев М.М. Отступное и новация в гражданском праве России: Автореф. дисс. канд. юрид. наук. М., 2010. С. 23-26; Крашенинников Е.А. к проблематике предоставления вместо исполнения. С. 35-36, 38-39.

34 Пояснительная записка «К проекту Федерального закона «О внесении изменений в части первую, вторую, третью и четвертую Гражданского кодекса Российской Федерации, а также в отдельные законодательные акты Российской Федерации»»// http://base.consultant.ru/cons/cgi/online.cgi?req=doc;base=PRJ;n=93951

35 См. п. 35 постановления Пленума ВС РФ и Пленума ВАС РФ от 4 декабря 2000 г. № 33/14 «О некоторых вопросах практики рассмотрения споров, связанных с обращением векселей»// Вестник ВАС РФ. 2001. № 2 .

36 См.: Крашенинников Е.А. к проблематике предоставления вместо исполнения. С. 40; комментарий к Гражданскому кодексу Российской Федерации. Часть первая/ Под ред. А.П. Сергеева. С. 834 (автор комментария - А.А. Павлов). 
тельства ${ }^{37}$, мы видимо имеем дело с очередным пороком юридической техники, который явно не красит законодательство и способен породить сложности правопонимания и правоприменения.

\section{III. Новация}

А. Новое обязательство. Новащия (замена обязательства) представляет собой соглашение, по которому стороны договариваются о замене одного связывающего их обязательства каким-либо другим, новым обязательством. В результате новации первоначальное обязательство прекращается, но участники не порывают правовых связей друг с другом, т. к. на базе прекращенного возникает согласованное между ними новое обязательство.

Описывая это новое обязательство, действующая редакция п. 1 ст. 414 ГК РФ указывает на «новый предмет или способ исполнения». к сожалению, данные характеристики зачастую воспринимаются участниками оборота и правоприменителями в качестве обязательных атрибутов новации. Наличие нового предмета или способа исполнения рассматриваются в качестве квалифицирующего признака новационного соглашения и используются для целей отграничения новации от смежных правовых явлений.

Вместе с тем, это очевидно не так. Во-первых, новацией следует считать не только изменение способа исполнения или предмета (например, замену денежного обязательства обязательством по передаче иного предмета), но и вида обязательства (например, новацию обязательства по передаче имущества обязательством по оказанию услуг). ${ }^{38}$

Во-вторых, в современных условиях достаточно остро стоит вопрос об отграничении новации от изменения отдельных условий обязательства, дополнений и уточнений ранее действовавшего договора. В отличие от новации, в последнем случае обязательство не прекращается, а продолжает действовать в измененном виде. Соответственно, такое изменение не влечет правовых последствий новации, способы обеспечения, установленные первоначальным обязательством, сохраняют свое действие и без специальной о том оговорки. При этом единственным универсальным критерием для разграничения новации и изменения договора является animus novandi (намерение обновить). Попытки представить в подобном качестве «новый предмет или способ исполнения» абсолютно бесплодны. Так, изменение способа исполнения (т.е. порядка совершения должником действий по исполнению обязательства) далеко

\footnotetext{
37 Концепция развития гражданского законодательства Российской Федерации// http://www.kadis.ru/texts/ index. phtml id $=42652 \&$ PrintVersion $=1$

38 Подробнее см.: Павлов А.А. Условия и последствия новации// Вестник ВАС РФ. 2006. № 8. С. 10.
} 
не всегда означает замену обязательства. В частности, предоставление покупателю отсрочки (рассрочки) оплаты очевидно прекращения обязательства не влечет. Равно не являются новацией случаи изменения срока исполнения ${ }^{39}$, порядка платежа, размера ответственности, дополнительного возложения обязанности по доставке и т.п. ${ }^{40}$

Напротив, новация принципиально допускает полную идентичность предмета и способа исполнения нового обязательства (например, при новации долга в заемное обязательство).

С учетом сказанного, содержащееся в Проекте изменений в ГК РФ предложение исключить из определения новации указание на «новый предмет или способ исполнения» новирующего обязательства абсолютно оправдано и заслуживает поддержки.

Б. Допустимость новации. Поскольку возможность заключения соглашения о новации вытекает из самого понятия договора, следует признать, что стороны свободны в решении вопроса о заключении такого соглашения. Ограничением такой свободы являются установленные законом случаи недопустимости новации. В частности, действующая редакция п. 2 ст. 414 ГК РФ содержит императивное правило, исключающее новацию в отношении обязательств по возмещению вреда, причиненного жизни или здоровью, а также алиментных обязательств. Причины такого запрета достаточно очевидны и кроются в строго целевом характере указанных обязательств, исключающем возможность их прекращения способом иным, нежели исполнение.

Действующая редакция п. 2 ст. 414 ГК РФ устанавливает соответствующие запреты абсолютным образом, распространяя их действие на алименты (возмещение вреда жизни или здоровью) как взыскиваемые по решению суда, так уплачиваемые добровольно, на основании соответствующего соглашения сторон.

Однако в отечественной литературе было высказано мнение о необходимости исключить алименты, уплачиваемые на основании алиментного соглашения, из под действия запрета п. 2 ст. 414 ГК РФ. Данный подход обосновывался ссылкой на п. 2 ст. 101 Ск РФ, допускающей возможность сторон в любое время по взаимному согласию измененить или расторгнуть соглашения об уплате алиментов. ${ }^{41}$ Подобная позиция достаточно сомнительна.

39 В виду некорректности правил п. 1 ст. 414 ГК РФ, высшая судебная инстанция вынуждена была обосновывать соответствующий вывод посредством достаточно спорного толкования категории «способ исполнения обязательства» (см. п. 1 Информационного письма Президиума ВАС РФ от 21 декабря 2005 г. № 103 «Обзор практики применения арбитражными судами статьи 414 ГК РФ»// Вестник ВАС РФ. 2006. № 4).

40 Подробнее см.: Павлов А.А. Условия и последствия новации. С. 10-11.

41 См.: комментарий к ГК РФ, части первой (постатейный)/ Под ред. О.Н. Садикова. 2-е изд. М., 2002. С. 787 (автор главы - О.Ю. Шилохвост). 
Во-первых, с сущностной точки зрения, соглашение об уплате алиментов не порождает алиментное обязательство (последнее возникает на основании юридического состава, включающего состояние родства или иное семейное состояние, а также, в большинстве случаев, нетрудоспособность и нуждаемость получателя алиментов), а лишь определяет порядок его исполнения. Соответственно, поскольку заключение алиментного соглашения не является основанием возникновения алиментного обязательства, расторжение этого соглашения не выступает основанием прекращения такого обязательства, и само по себе не погашает алиментную обязанность соответствующего лица. Во-вторых, с позиций политики права, ослабление указанного запрета выхолащивает его сущность, поскольку создает достаточно простую и очевидную возможность «легального» обхода императивных норм законодательства (ст. 411 ГК РФ), и тем самым, нарушения интересов получателей алиментов. Так, достаточно новировать алиментное обязательство в заемное, а затем погасить последнее зачетом встречного однородного требования.

К сожалению, эти аргументы не были услышаны составителями концепции развития гражданского законодательства. Последние сочли необходимым, в целях гармонизации с новыми диспозитивными нормами семейного законодательства, снабдить правило о недопущении новации в отношении обязательств по возмещению вреда, причиненного жизни или здоровью, и по уплате алиментов (п. 2 ст. 414 Гк РФ) оговоркой «если иное не установлено законом».

Само данное предложение не бесспорно, и отражает, скорее частную позицию разработчиков концепции, нежели современное состояние отечественной цивилистической доктрины. Однако нормативная техника воплощения этой идеи в Проекте изменений в ГК РФ, оказалась еще более радикальной и неудачной. Пункт 2 ст. 414 ГК РФ, устанавливающий запрет новации «целевых» обязательств, планируется исключить вовсе. А вместо него, общее правило п. 1 ст. 414 ГК РФ предложено дополнить «обратной» оговоркой: «Обязательство прекращается соглашением сторон о замене первоначального обязательства, существовавшего между ними, другим обязательством между теми же лицами (новация), если иное не установлено законом или не вытекает из существа отношений».

Этот подход не выдерживает критики. Он сводит на «нет» защиту интересов граждан, нуждающихся в денежных средствах в целях обеспечения своего существования как личности (получателей алиментов, потерпевших от причинения вреда здоровью или вследствие потери кормильца). Он лишает оборот прозрачности и стабильности, поскольку достоверно утверждать существо какого отношения исключит применение общего правила оказывается невозможно. Это грозит как потенциально чрезмерным расширением круга обяза- 
тельств, новация, которых будет признана недопустимой, так и напротив, их возможно чрезмерным сужением. С точки зрения политики права, в условиях свободы договора, любое ее ограничение много целесообразнее устанавливать прямо, нежели посредством витиеватой отсылки к «существу отношений». Наконец, буквальное прочтение предлагаемой редакции п. 1 ст. 414 ГК РФ вообще способно породить сомнения относительно направленности фразы «если иное не установлено законом или не вытекает из существа отношения»: касается ли она сферы применения новации или ее эффекта. Все это позволяет оценить данную «новеллу» как крайне неудовлетворительную. 
SOME OF THE ISSUES OF THE REFORM INSTITUTE OF TERMINATION OF OBLIGATIONS

This article is dedicated to the issues of termination of obligations. The author considers the Russian law of set-off, datio in solutum, novation. Special attention is dedicated to the Draft of amendments to the Civil code of Russian Federation. In this paper estimation is given to proposals to reform the institute of termination of obligations, marked with their advantages and disadvantages.

Key words:

Obligation; termination of obligations; set-off; datio in solutum; novation; Draft of amendments to the Civil code of Russian Federation. 